\title{
Dietary Nutrient Intake and Obesity Prevalence among Native American Adolescents
}

\author{
Hanchu Dai, Randy Song, Margaret Barth, Shasha Zheng \\ College of Health Science, California Baptist University, California, United State of America
}

\begin{tabular}{l}
\hline \hline Article Info \\
\hline Article history: \\
Received Feb 2, 2018 \\
Revised May 15, 2018 \\
Accepted Jun 8, 2018 \\
\hline
\end{tabular}

\section{Keyword:}

Native American adolescents Nutrition intake Obesity

\begin{abstract}
The prevalence of obesity among adolescent minority populations has been long recognized, but little research has been done on Native Americans adolescents. Using anthropometric measurements and dietary assessments, the findings within each study have shown to obtain baseline measures to determine the prevalence of obesity within the Sherman Indian High School's Native American adolescent population. Data of each assessment appear to be of use for predicting obesity and creating effective future interventions. Compiling data using the Harvard School of Public Health Youth/Adolescent Questionnaire (HSPH YAQ), a semi-quantitative food frequency questionnaire allowed significant data to be found between normal and obese weight students. Utilizing each finding allows more effective ways of targeting and reversing the inclining rate of obesity among Native American adolescents. Results show that antioxidants being examined on such as vitamin $\mathrm{E}$ and lycopene are beneficial in lowering the obesity rate among Native American adolescents. Levels of fiber, thiamin and folate consumption was significantly lower among the obese population in Sherman Indian High School's Native American adolescents. Moreover, dietary mineral intake was shown to be lower among obese Native American adolescents comparing with the normal weight group. The results suggested that dietary consumption of these nutrients might correlate and predict obesity and lead to the development of effective interventions for Native Americans. This study also found the effects of total fiber and vitamin B in diets with lifestyle intervention in prediabetic adults, showing that total fiber intake among the normal weight students is significantly higher than obese students, indicating that fiber and vitamin profile could be important determinants of the effect of dietary intervention.
\end{abstract}

Copyright $\left({ }_{0} 2018\right.$ Institute of Advanced Engineering and Science. All rights reserved.

\section{Corresponding Author:}

Shasha Zheng,

Department of Pubic Health Sciences,

California Baptist University,

8432 Magnolia Ave, Riverside, CA, 92504, United States of America.

Email: szheng@calbaptist.edu

\section{INTRODUCTION}

Obesity is a pandemic that has soared in recent years. In the U.S., obesity has created numerous problems that have led to many health concerns [1]. These health risks include diabetes mellitus, hypertension, cardiovascular disease (CVD), stroke, and some forms of cancer which are preventable by diet [2]. Demonstrating sound nutrition and education can decrease the inclining rate of obesity. According to data from the National Health Interview Survey in 2015, 30.4\% of U.S. adults aged 20 and over were obese. This condition is damaging towards the affected individuals and also generates more medical costs for the obese population. The estimated annual cost of obesity in the U.S. was $\$ 190.2$ billion in 2017 [3]. The health share of gross domestic product (GDP) was expected to reach 10.5 percent in 2017 . Obesity also stunts healthy 
behavior patterns which affects physical and emotional health. For adolescents, their dietary habits will be carried on into adulthood, which make their growing year's crucial periods for establishing healthy behaviors [4]. Approximately $17 \%$ of children and adolescents aged 2-19 years are obese and this phenomenon is more common among certain racial and ethnic groups; non-Hispanic white, non-Hispanic black, and Hispanic adults and youth have a higher prevalence to obese than other people groups [5].

In particular, the rate of obesity is remaining high among Native Americans, at 31.2\%. In communities surveyed by the Racial and Ethnic Approaches to Community Health (REACH) 2010 Risk Factor Survey, more than one-third of US Native American men and women were obese whereas approximately one-fifth of adults were obese on the national level [6]. As childhood and adolescent obesity rates have been closely observed, recent reports among Native American adolescents have been of interest.

In the last ten years, US population-based surveys have shown that adolescents fail to meet dietary recommendations for overall nutritional status. Food intakes associated with healthier diets to support nutrition status often include higher intakes of fruit and vegetables, which are rich in minerals, macronutrients, and antioxidants. The current daily recommendations for fruit and vegetables in the adolescent diet are two cups of fruit and three cups of vegetables. However, less than 1 in 10 adolescents meet the recommended fruit and vegetables intake according to The Third National Health and Nutrition Examination Survey (NHANESIII) [7]. Research shows an estimated $70 \%$ of all cancer is attributed to diet, and diets high in fat and low in fruits, vegetables, and grains are associated with increased risk of cancer [8]. In contrast, Native Americans are not included in national nutritional monitoring systems, so information is especially rare concerning obesity of Native Americans, particularly adolescents. In the past few generations, it is believed that obesity among American Indians is associated with the relative abundance of high-fat, high calories foods and the rapid change to sedentary lifestyles [9].

The few studies of American-Indian youth, there are correlations that have shown that over intake on some nutrients, including saturated fats, trans fats as well as foods that are high in sodium and added sugars, have posed an increased risk for adverse levels of several cardiovascular disease's risk factors such as blood lipids, insulin, and blood pressure [9]. By studying obese individuals, multivitamin and mineral supplementation have been found to reduce fatness and improve serum lipid profiles, possibly through increased energy expenditure and fat oxidation [10]. In a study of Navajo children and adolescents ranging from 12 to 19 years of age, Freedman and his team found that Native American adolescents in their survey had a $5-10 \mathrm{mg} / \mathrm{dL}$ lower median level of HDL cholesterol, and a $30 \mathrm{mg} / \mathrm{dL}$ higher median triglyceride level compared to general adolescents in United States; overweight Navajo adolescents had a fivefold greater risk for elevated triglyceride levels than other adolescents [11]. The relationship between lipids, lipoproteins and blood pressure and body weight suggests that the increased population having diabetes mellitus is highly related to their diet, which is crucial for individuals and organizations on future intervention.

It is suggested that mineral supplementation during adolescence may improve physical growth and development, including muscle contraction, nerve signal conduction and bone health [12]. Moreover, correlating dietary mineral intakes with overall psychiatric functioning in adults, the results indicated that higher levels of mental function associated with a higher intake of minerals [13]. This detailed analysis in a clinically diagnosed sample was consistent with prior surveys, revealing an association between higher levels of nutrient intakes and better mental health. A study based on the effects of total fiber diets with lifestyle intervention in prediabetic adults also proved thata regular fiber-rich diet, which indicated that fiber profile could be an important determinant of the effect of dietary intervention, had a pronounced effect on glucose regulation and resulted in a significant fall in glycaemia [14]. However, the correlation between these nutrients and adolescents' health is still under investigation. In our study, we assessed the effects of multiple micronutrients' dietary intake among Native American adolescents on their obesity levels, especially for minerals, fiber, thiamin, and folate.

\section{RESEARCH METHOD}

The study was performed at Sherman Indian High School, Riverside, California. Sherman Indian High School is an off-reservation boarding high school for Native Americans. The study population consisted of 183 male and female Native American adolescents, 14-18 years of age, representing 43 different tribes from across the United States. We conducted a baseline anthropometric measurement of height $(\mathrm{cm})$, weight $(\mathrm{kg})$, waist circumference $(\mathrm{cm})$, triceps skin-fold measures, including tricep and calf skin-fold measures from the Native American students and compared these data with NIH standardized protocols to assess weight classification by body mass indices for our population. Obesity rate within Native American adolescents in Sherman Indian High School was calculated using BMI $\left(\mathrm{kg} / \mathrm{m}^{2}\right)$ and compared with NHANESIII data. The collection of anthropometric and dietary data was scheduled at each of the four dormitories for eight weeks, conducted by trained faculty and student intern researchers. 
To examine Native American adolescents' nutrients intake and to evaluate the differences in the intake levels between normal and obese weight students (BMI), we used the Harvard School of Public Health Youth/Adolescent Questionnaire (HSPHYAQ), a semi-quantitative, self-administered food frequency questionnaire with a reasonable ability to assess the eating habits of older children and adolescents over time. For insuring the validity and reliability of this instrument, the complete surveys were prepared for scanning by the Harvard T.H. Chan School of Public Health Nutrition Department, then the Data analysis of dietary nutrients intake were conducted at California Baptist University using R statistical software.

\section{RESULTS AND ANALYSIS}

\subsection{Dietary Assessment}

The first phase of the study was the anthropometric assessment, which showed that, among Native American adolescents in Sherman Indian High School, $35.4 \%$ of the males and $41.7 \%$ of the females were classified as obese. The obesity rate among the Native American students in this study was $38.3 \%$. This rate is double of the national rate reported for adolescents. Part of data in this study has been published based on the results obtained on antioxidants, vitamin E and lycopene, which showed the antioxidant intake level was significantly lower among obese Native American adolescents. Dietary intake of antioxidant in Native American adolescents were recorded from fruits and vegetables, while the resources were not diverse.

Results are expressed as mean \pm SEM. Comparisons between normal and obese groups were performed by two-tailed t-test. Significance testing was set at $\mathrm{p}$-value $<0.05$. All results are reported in normal or obese weight classification. The vitamin C intake was $202.91 \mathrm{mg} /$ day amongst normal weight students, $144.84 \mathrm{mg} /$ day amongst normal weight students; both were greater than the U.S. recommended dietary allowance (RDA) (65-75mg/day). However, the differences between normal and obese adolescents is significant (p-value<0.05). The vitamin E intake among Sherman Indian High School's Native American students is $3.14 \mathrm{mg} /$ day in normal weight students, $2.28 \mathrm{mg} /$ day in normal weight students. Both the normal weight and obese Native American adolescents in our study consumed significantly less than the RDA of vitamin E per day, which is $15 \mathrm{mg} /$ day, and the difference between the two groups' intake of vitamin $\mathrm{C}$ is significant (p-value $<0.05$ ). Lycopene average intake among normal adolescents is $7.62 \mathrm{mg} / \mathrm{day}$, compared to $5.5 \mathrm{mg} /$ day among obese adolescents; the difference in in lycopene intake between two groups was significant (p-value<0.05) [15].

Recently, we further analyzed dietary intake for minerals among Native American adolescents (Figure 1). Figure $1 \mathrm{~A}$ shows the results on iron intake, which indicated a significant difference between the dietary intake of Iron among normal $(18.7 \mathrm{mg} /$ day) and obese $(13.5 \mathrm{mg} /$ day) weight Native American adolescents ( $\mathrm{p}$-value $=0.028$ ). The U.S. RDA for Iron is $16.3 \mathrm{mg} /$ day, which is significantly higher than the intake amount of obese weight adolescents. Figure 1B shows the dietary intake of Magnesium among this population was $438.8 \mathrm{mg} /$ day in normal weight students, while the mean usual intake in the obese group was $333.4 \mathrm{mg} / \mathrm{day}$, significantly lower than the normal weight group ( $\mathrm{p}$-value=0.026). The U.S. RDA of Magnesium is $410 \mathrm{mg} / \mathrm{day}$ for adolescents in this age range, which showed the deficiency on magnesium in the obese group of Native American adolescents. Figure 1C shows the dietary potassium intake among this population in the normal group was $3888.5 \mathrm{mg} / \mathrm{day}$, while the mean intake in the obese group was $2932 \mathrm{mg} / \mathrm{day}$, which is significantly lower than the U.S. RDA, 4700mg/day (p-value=0.026).

Levels of fiber, thiamin and folate consumption were also examined in this study. Figure $2 \mathrm{~A}$ shows the total fiber intake among normal weight adolescents was significantly higher than total fiber intake among obesity adolescents, which is $28 \mathrm{~g} /$ day in the normal group and $21 \mathrm{~g} /$ day in the obesity group. The RDA for adolescents' fiber daily intake is $25 \mathrm{~g}$ /day, which is not met in the obese group of adolescents. Figure $2 \mathrm{~B}$ shows thiamin daily intake among normal weight Native American adolescents is $2.5 \mathrm{mg} /$ day, which is significantly higher than the obese group's intake, which is $1.75 \mathrm{mg}$ /day. Both groups met the U.S. RDA for thiamin, $1.2 \mathrm{mg} /$ day. Figure 2C shows folate intake among normal weight Native American adolescents is 600ug/day, which is significantly higher than the obese group, $445 \mathrm{ug} /$ day. The results indicated that the intake of total fiber, along with thiamin and folate should be increased among Native American adolescents. The results from our research suggested that fiber may play an important role in determining future obesity and metabolic syndrome. Further research is needed to confirm our findings and identify the most effective ways of providinghealthy food services for adolescents.

\subsection{Statistical Analysis}

Results are expressed as mean SEM. Comparisons between normal and obese groups were performed by two-tailed t-test. Significance testing was set at $\mathrm{p}$-value $<0.05$. All results are reported in normal or obese weight classification. Figure 1 shows dietary intake of iron, magnesium and potassium while Figure B informs Dietary intake of total fiber, thiamin and folate among Native American adolescents. 

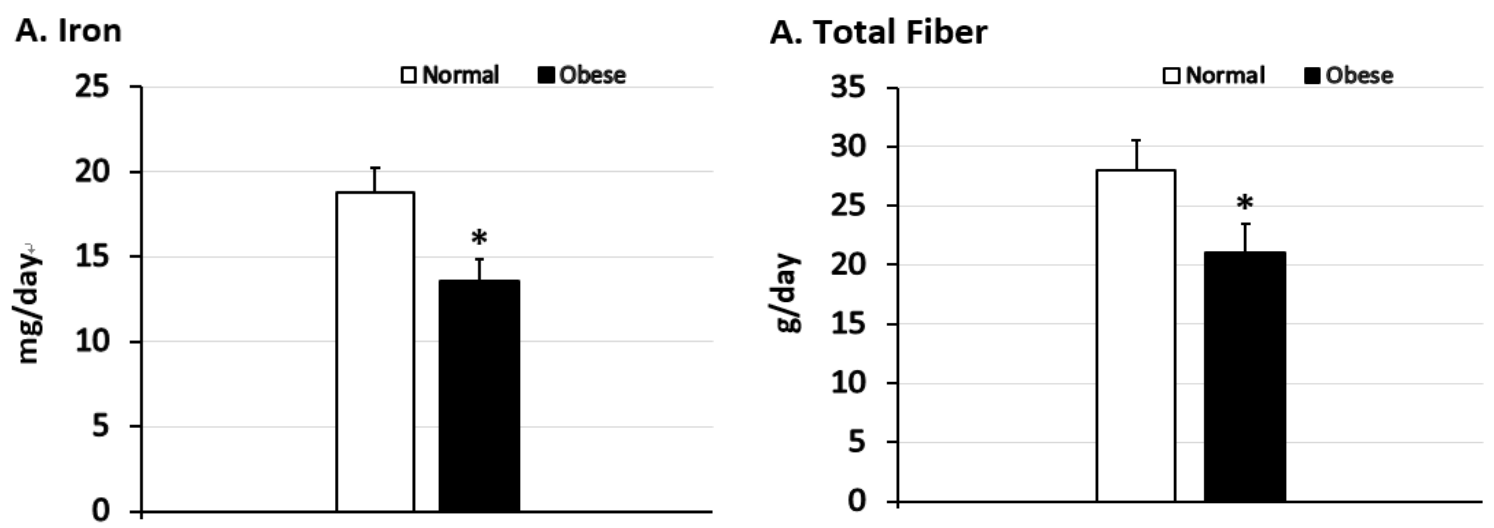

\section{B. Magnesium}

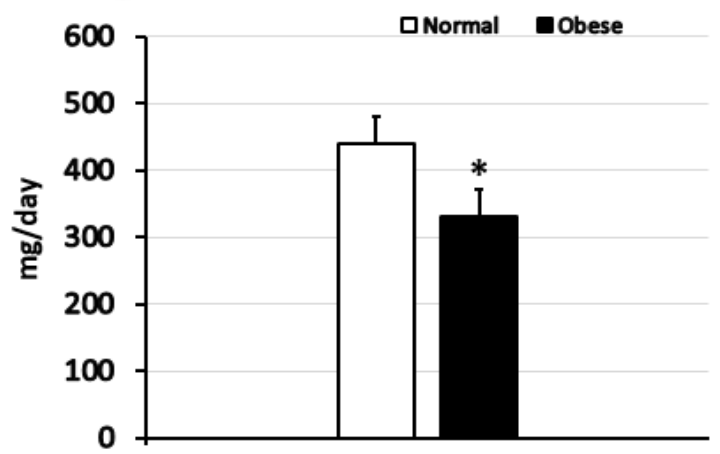

\section{Potassium}

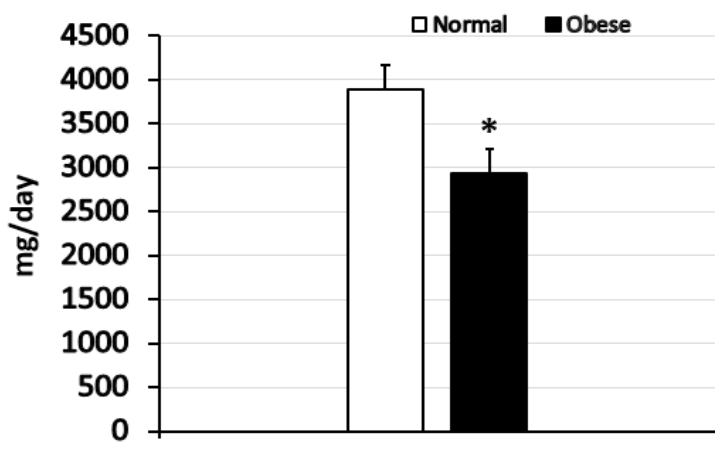

Figure 1. Dietary intake of iron (A), magnesium (B) and potassium (C) among Native American adolescents
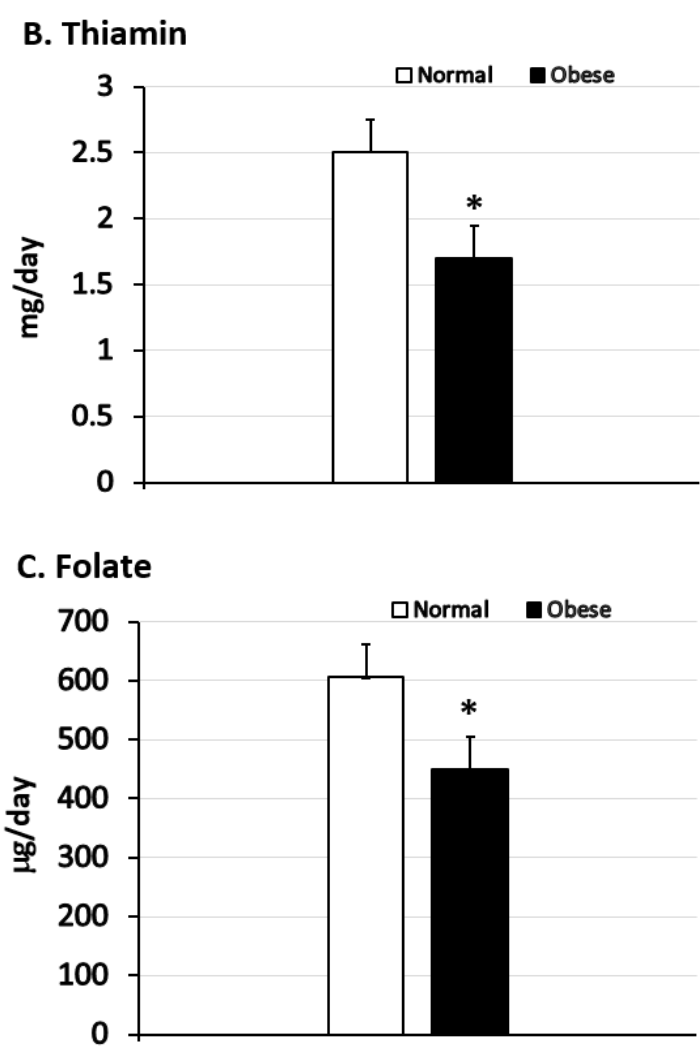

Figure 2. Dietary intake of total fiber (A), thiamin (B) and folate (C) among Native American adolescents

\section{DISCUSSION}

Our results suggested that Native American adolescents could lower their risk of obesity by gaining greater access to healthy food, along with nutrition education on the health benefits of increasing fruit and vegetable intake from school. Adolescent obesity brings not only serious long-term health implications to adolescents' future lives, but also the potential to lead to a socioeconomic trajectory of lower earnings and household income [17]. The results indicated that the intake of muiltivitamins, minerals, total fiber, along with thiamin and folate should be increased among Native American adolescents.

The results from our research suggested that fiber, folate and thiamin may play an important role in determining future obesity and metabolic syndrome. Furthermore, Malin found that food rich in thiamin, folate and fibers, such as whole grains, may reduced diabetes risk and the mechanisms appear to reduce post-prandial blood glucose and peripheral insulin resistance, linking to enhanced metabolic flexibility [18]. Further research is needed to confirm our findings and identify the most effective ways of providing healthy food services for adolescents. An intervention in collaborating with school administration and food service provider would be beneficial in order to help students keep their healthy levels. 


\section{CONCLUSION}

This study revealed that antioxidants such as vitamin C, vitamin $\mathrm{E}$ and lycopene, are beneficial in lowering the obesity rate among Native American adolescents. Dietary intake of the minerals iron, magnesium and potassium was generally shown to be lower among obese Native American adolescents. Levels of fiber, thiamin and folate consumption were significantly lower among obesity population in Sherman Indian High School's Native American adolescents, which indicated the correlation between higher level of nutrients intake play important roles in lowering the obesity rate among Native American adolescents.

Obesity is a preventable prevalence that has encapsulated our youth, the complex interactions of genetic and environmental factors have been discovered to lead to the onset of obesity. Obese Native American adolescents in Sherman Indian High School did not meet the RDA intake for iron, magnesium, and potassium in this research. Our results suggest that this population could benefit from improved availability of healthy food, such as vegetables and fruits which are rich in these minerals, along with nutrition education on the importance of these nutrients. Availability and access to healthy foods high in antioxidants, fiber, and Vitamin $\mathrm{B}$ is required for Native American adolescents. Using data comparing to baseline and national surveys have allowed new suggestions and possible education interventions among the Native American population. The results indicated that the intake of total fiber, along with thiamin and folate should be increased among Native American adolescents.

\section{ACKNOWLEDGEMENT}

We would like to express our thanks to Sherman Indian High School; to Benjamin Knisley for statistical analysis; and to J W \& Ida M Jameson Foundation 2017 for their collaboration and support.

\section{REFERENCES}

[1] Hurt, R.; Kulisek, C.; Buchanan, L.; McClave, S.; , "The Obesity Epidemic: Challenges, Health Initiatives, and Implications for Gastroenterologists," Gastroenterology \& Hepatology, vol.6, no.12, pp.780-792, 2010.

[2] World Health Organization [Internet]. Diet, nutrition and the prevention of chronic diseases. WHO Techical Report series 916; 2013. Available from https://www.ncbi.nlm.nih.gov/pubmed/12768890.

[3] Finkelstein, E.; Trogdon, J.; Cohen, J.; Dietz, W.; , [Internet]. Annual Medical Spending Attributable To Obesity: Payer-And Service-Specific Estimates, 2009. Available from

https://www.healthaffairs.org/doi/abs/10.1377/hlthaff.28.5.w822?url_ver=Z39.882003\&rfr_id=ori\%3Arid\%3Acros sref.org\&rfr_dat=cr_pub\%3Dpubmed.

[4] Schwarz, S.; Peterson, J.; , [Internet]. Adolescent Obesity in the United States: Facts for Policymakers, 2010. Available from http://www.nccp.org/publications/pub_977.html.

[5] Ogden, C.; Carroll, M.; Fryar, C.; Flegal K.; , "Prevalence of obesity among adults and youth: United States, 20112014," U.S. Department of Health and Human Services, vol.219, pp.1-8, 2015.

[6] Schell, L.; Gallo, M.; , "Overweight and Obesity Among North American Indian Infants, Children, and Youth," American Journal of Human Biology: The Official Journal of the Human Biology Council, vol.24, no.3, pp.302313, 2012.

[7] Centers for Disease Control and Prevention (CDC), National Center for Health Statistics (NCHS), National Health and Nutrition Examination Survey Data, Hyattsville, MD: U.S. Department of Health and Human Services, Centers for Disease Control and Prevention.

[8] Noia, J.; Schinke, S.; Contento, I.; , "Dietary patterns of reservation and non-reservation Native American youths," Ethnicity \& Disease, vol 15, no. 4, pp.705-12, 2005.

[9] Story, M.; Stevens, J.; Himes, J.; Stone, E.; Rock, B.; Ethelbah, B.; Davis, S.; , “Obesity in American-Indian children: Prevalence, consequences, and prevention," Preventive Medicine: An International Journal Devoted To Practice And Theory, vol.37, no.6, pp.3-12, 2003.

[10] Li, Y.; Wang, C.; Zhu, K.; Feng, R.; Sun, C.; , "Effects of multivitamin and mineral supplementation on adiposity, energy expenditure and lipid profiles in obese Chinese women," International Journal Of Obesity, vol.34, no.6, pp.1070-1077, 2010.

[11] Freedman, D.; Serdula, M.; Percy, C., Ballew C., White, L.; , "Obesity, levels of lipids and glucose, and smoking among Navajo adolescents," The Journal of Nutrition, vol.127, suppl pp.2120-2127, 1997.

[12] Hoxha, R.; Islami, H.; Qorraj-Bytyqi, H.; Thaçi, S.; Bahtiri, E.; , "Relationship of Weight and Body Mass Index with Bone Mineral Density in Adult Men from Kosovo," Materia Socio-Medica, vol.26, no.5, pp.306-308, 2014.

[13] Davison, K.; Kaplan, B.; , "Nutrient intakers are correlated with overall psychiatric functioning in adults with mood disorders," The Canadian Journal Of Psychiatry/La Revue Canadienne De Psychiatrie, vol.57, no.2, pp.85-92, 2012.

[14] Dodevska, M.; Sobajic, S.; Djordjevic, P.; Dimitrijevic-Sreckovic, V.; Spasojevic-Kalimanovska, V.; Djordjevic, B., "Effects of total fibre or resistant starch-rich diets within lifestyle intervention in obese prediabetic adults," European Journal Of Nutrition, vol.55, no.1, pp.127-137, 2016.

[15] Knisely, B.; Crosby, G.; Barth, M.; Carothers, L.; , "Health Risk of Obesity in Native American Adolescents," International Journal of Public Health Science, vol.4, no.2, pp.94-101, 2015. 
[16] Perez, M.; Knisley, B.; Crosby, G.; Zheng, S.; Barth, M.; , "Obesity Prevalence and Dietary Intake of Antioxidants in Native American Adolescents," International Journal of Public Health Science, vol.5, no.3, pp.222-227, 2016.

[17] Ritterman-Weintraub, M.; Fernald, L.; Goodman, E.; Guendelman, S.; \& Adler, N.; , "Obesity-Related Behaviors among Poor Adolescents and Young Adults: Is Social Position Associated with Risk Behaviors?” Epidemiology, vol.3, pp.224, 2015.

[18] Malin, S.; Kullman, E.; Sceisi, A,; Haus, J.; Filion, J.; Pagadala, M.; , "A Whole-Grain Diet Reduces Peripheral Insulin Resistance and Improves Glucose Kinetics in Obese Adults: A Randomized-Controlled Trial." Metabolism: Clinical and Experimental, vol.82, no.01, pp.111-117, 2018. 